\title{
Linguistic Extension for Group Multicriteria Project Manager Selection
}

\author{
Javad Dodangeh,, ${ }^{1,2}$ Shahryar Sorooshian, ${ }^{1}$ and Ali Reza Afshari ${ }^{3}$ \\ ${ }^{1}$ Faculty of Technology, University Malaysia Pahang, 26300 Pahang, Malaysia \\ ${ }^{2}$ Department of Industrial Engineering, Qazvin Branch, Islamic Azad University, Qazvin, Iran \\ ${ }^{3}$ Department of Industrial Engineering, Shirvan Branch, Islamic Azad University, Shirvan, Iran
}

Correspondence should be addressed to Shahryar Sorooshian; sorooshian@gmail.com

Received 14 December 2013; Accepted 12 February 2014; Published 24 March 2014

Academic Editor: Farhad Hosseinzadeh Lotfi

Copyright (C) 2014 Javad Dodangeh et al. This is an open access article distributed under the Creative Commons Attribution License, which permits unrestricted use, distribution, and reproduction in any medium, provided the original work is properly cited.

\begin{abstract}
Qualified human resource selection is one of the organizational key success factors. Since choosing the best candidate to fill the defined vacancy in a company is a complex task, intelligence analytical methods would be required to deal with this important issue. Regarding the vagueness and uncertainty of human resource selection process, it requires the linguistic extension of multicriteria decision making (MCDM) models for robust recruitment. This research is aimed to develop a fuzzy MCDM model for linguistic reasoning under new fuzzy group decision making. The new linguistic reasoning for group decision making is able to aggregate subjective evaluation of the decision makers and hence create an opportunity to perform more robust human resource selection procedures. A numerical example demonstrates possibilities for the improvement of human resource management and any other business decision areas through applying the proposed model.
\end{abstract}

\section{Introduction}

Traditional human resource selection method uses experimental and statistical techniques approach. After using the experimental approach, decision makers, with the help of their experiences and understanding of the job specifications, select the human resource. In the statistical techniques approach decision makers get decision through the arrangement of test scores and the measurement of candidates' accomplishment. Interviewing related candidates is one of the techniques concerning human resource selection. Robertson and Smith [1] present notable ability and availability of interviews to predict the performance of the human resource in the job. A number of studies deal with making better human resource selection decisions in organizations. These studies are based on interviews, work sample tests, assessment centers, resumes, job knowledge tests, and personality tests in human resource management [2], while multicriteria decision making (MCDM) techniques were used by only a few of them [3].

Searching for MCDM, fuzzy logic, and human resource selection separately has a few results in research databases.
But searching for the keywords together results in few researches. Authors could not find any article from our research database search for the three keywords of MCDM, fuzzy logic, and project manager selection! Lack of research in this field guides authors to contribute to the knowledge of human resource selection, with current developed linguistic extension of MCDM for group project manager selection problem. The usage of fuzzy linguistic variables to conduct evaluation will enhance the efficiency of decision making by reducing error in utility values in human resource selection. The main objective of this research is to develop a fuzzy MCDM model for linguistic reasoning under new fuzzy group decision making for candidate evaluation in project manager selection process. Since the modeling of fuzzy linguistic extension of MCDM for group project manager selection problem is in essence non-existent, this study has aimed to fulfill several particular contributions comprising

(i) determining the explicit criteria and subcriteria regarding the project manager selection problem;

(ii) employing fuzzy linguistic extension of group MCDM for project manager selection problem 
under uncertainty. The new linguistic reasoning for group decision making is able to aggregate subjective evaluation of the decision makers and hence create an opportunity to perform more robust human resource selection procedures.

In Section 2, the literature of human resource selection and MCDM is reviewed. The proposed model and a real case study are discussed in Sections 3 and 4, respectively. Finally, Section 5 provides concluding remarks.

\section{Literature Review}

MCDM deals with decision problems with a number of decision criteria and it is a branch of operations research models, which is divided into multiattribute decision making (MADM) and multiobjective decision making (MODM). Each of the above categories consists of several methods. Each method can also be classified as deterministic, stochastic, and fuzzy methods with its own characteristics. Sometimes researchers may use a combination of the methods. The methods can be classified as a single or group decision making methods based on the number of decision makers [4]. Some of the contributors applied AHP $[5-8]$, ANP $[9,10]$, DEMATEL [11], TOPSIS [12], and Expert Systems [2, 13-18] in human resource selection.

The decision makers have difficulties in assigning crisp values as scorings to the criteria, because human resource selection is a human problem in resource management. The main characteristic of human resource selection problem is the fuzziness. Compared with regular crisp set method, the fuzzy linguistic approach represents qualitative aspects as linguistic values by means of linguistic variables $[19,20]$. Linguistic reasoning requires fewer assessments information; it requires very few assumptions to be satisfied; furthermore, by including the degree of importance for decision makers, these tools are very realistic [21]. Thus, in stage two, linguistic MCDM is employed.

Some of the researchers extend the typical MCDM methods to the fuzzy environment in human resource selection. In order to represent the scorings of the alternatives or the importance of criteria in fuzzy sentence, there is a significant volume of studies that extended fuzzy AHP [22, 23], fuzzy ANP [24], and fuzzy TOPSIS [3, 25-30] to human resource selection.

When decision makers do not want to or are not able to represent their preferences in form of quantitative evaluations, fuzzy linguistic modeling can be used for qualitative evaluations. In fuzzy linguistic modeling, we use linguistic variables [31] whose values are words or sentences (not numbers). For example, in human resource selection, communication skill is a criterion that can be considered as a linguistic variable. Its linguistic values are poor, fair, and good. By a fuzzy triangular number, each linguistic value can be represented. Some authors [32-36] have used fuzzy linguistic variables or fuzzy linguistic rules for human resource selection.

The MCDM has been used in selecting project managers. For example, Chen and Cheng [37] developed a fuzzy MCDM method for information system project manager selection. $\mathrm{Bi}$ and Zhang [38] analyzed the significance of choosing an eligible project manager in their study. They tried to quantitatively assess the ability and quality of a project manager by implementing fuzzy analytical hierarchy process which was based on triangular fuzzy numbers. Whatever they did is considered as a reliable and scientific method in terms of selecting the right person for project manager. Hui et al. [39] tried to demonstrate a suitable competencybased framework. The rationality of this paper is examined in the methodology section which was constructed by principle component analysis. All these efforts make this study prominently valuable and referential in project manager selection. By implementing principles of fuzzy mathematics, an extensive assessment model of project manager candidates has been established by Zhao et al. [40]. Zavadskas et al. [41] developed multicriteria methodology for project manager selection based on grey criteria. Zhao et al. [42] adopted fuzzy comprehensive evaluation methods in the selection of a project manager. Rashidi et al. [43] combined fuzzy systems, ANNs, and genetic algorithm for choosing a qualified project manager.

From the decision science point of view, many scholars have dealt with the project manager selection problem. To handle this decision making problem, they combined techniques from operational research with artificial intelligence fields. Expert systems, fuzzy linguistic variables, neural networks, and MCDM techniques have been used as methodology. The investigation of applying various methods for project manager selection problem indicates that most of the methods have ignored the efficient evaluation step. Therefore, developing a fuzzy linguistic extension of group MCDM for project manager selection problem under uncertainty is required for performing more robust human resource selection procedures.

\section{Proposed Model}

3.1. Fuzzy Multicriteria Decision Making (FMCDM). Decision making is the most important scientific, social, and economic endeavor, for making consistent and correct choices. In fact, it is the essence of any decision process that imbue with uncertainty [44]. MCDM is one of the well-known topics of decision making. Fuzzy logic provides a useful way to approach an MCDM problem. Very often in MCDM problems, data are imprecise and fuzzy. In a real-world decision making situation, the application of the classic MCDM method may face serious practical constraints, because of the criteria containing imprecision or vagueness inherent in the information. For these cases, the FMCDM method has been developed [45]. Applications of fuzzy MCDM are used in engineering and management in several studies [44-52]. In general, fuzzy MCDM matrix can be illustrated in Table 1.

3.2. Experts Group and Criteria Weights. The MCDM problem has some objectives that should be recognized by decision makers. All MCDM methods require information that should be gained based on relative importance of the criteria. 
TABle 1: Fuzzy MCDM matrix.

\begin{tabular}{lcccc}
\hline Alternatives & & Criteria & & \\
& $C_{1}=\{$ fuzzy set $\}$ & $C_{2}=\{$ fuzzy set $\}$ & $C_{3}=\{$ fuzzy set $\}$ & $C_{m}=\{$ fuzzy set $\}$ \\
\hline$A_{1}$ & $A_{11}=\{$ fuzzy set $\}$ & $A_{12}=\{$ fuzzy set $\}$ & $A_{13}=\{$ fuzzy set $\}$ & $A_{1 m}=\{$ fuzzy set $\}$ \\
$A_{2}$ & $A_{21}=\{$ fuzzy set $\}$ & $A_{21}=\{$ fuzzy set $\}$ & $A_{23}=\{$ fuzzy set $\}$ & $A_{2 m}=\{$ fuzzy set $\}$ \\
$\vdots$ & $\vdots$ & $\vdots$ & $\vdots$ & $\vdots$ \\
$A_{n}$ & $A_{n 1}=\{$ fuzzy set $\}$ & $A_{n 2}=\{$ fuzzy set $\}$ & $A_{n 3}=\{$ fuzzy set $\}$ & $A_{n m}=\{$ fuzzy set $\}$ \\
\hline
\end{tabular}

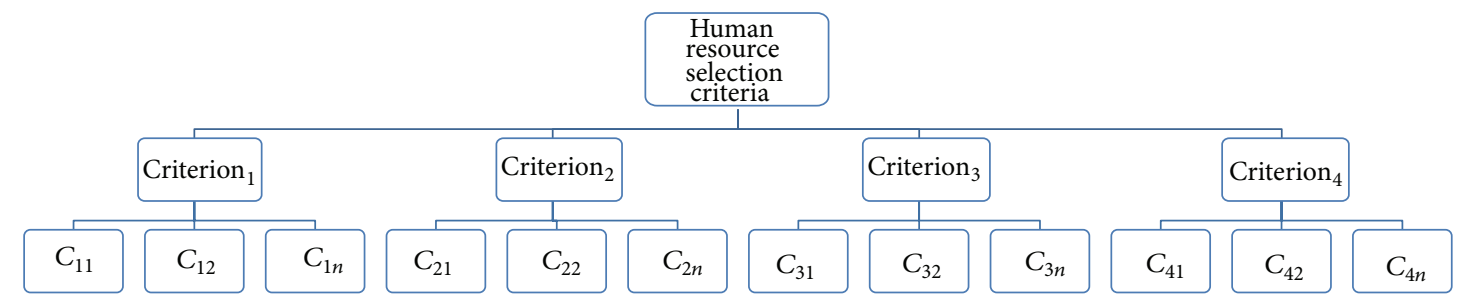

FIGURE 1: Hierarchical criteria.

Objective weights can be allocated directly to objectives by a decision maker group or by scientific methods. These weights specify relative importance of every criterion.

Usually groups are classified based on their different levels in social status, knowledge, and work experience. So, every factor in special subject that causes increase or decrease of an idea's weight should be considered. In this regard, allocating different weights to opinions regarding their knowledge and experience in relation to that subject seems necessary. Our study uses hierarchical objectives for identifying criteria weights as can be seen in Figure 1.

For this process, the study has to determine the weights of criteria and subcriteria using expert opinions. The final weights of criteria are determined by implementing the geometric average method. The method for calculation is shown as follows:

$$
T W_{C i j}=\sqrt{W_{C i} \cdot W_{C i j}},
$$

where $T W_{C i j}$ is final weight of each criterion, $W_{C i}$ is weight of criterion, and $W_{C i j}$ is weights of subcriterion [53].

3.3. Algorithm of Human Resource Selection. In this section, model inputs, processes, and output (selection of human resource) are systematically outlined. In the subsequent flowchart (Figure 2), the components of accomplished algorithm have been depicted. On the basis of algorithm of modelling process for selecting human resource, different phases are explained as follows.

Phase 1 (selecting relevant criteria and subcriteria). Based on expert panel opinions and data and information gained from a company, the criteria and subcriteria are formed for human resource selection. Members of the experts' panel who have significant information about personnel and the strategic direction of a company are chosen. There are several methods such as Delphi or Nominal Group Technique (NGT) which can be used to identify the human resource based on experts opinions.

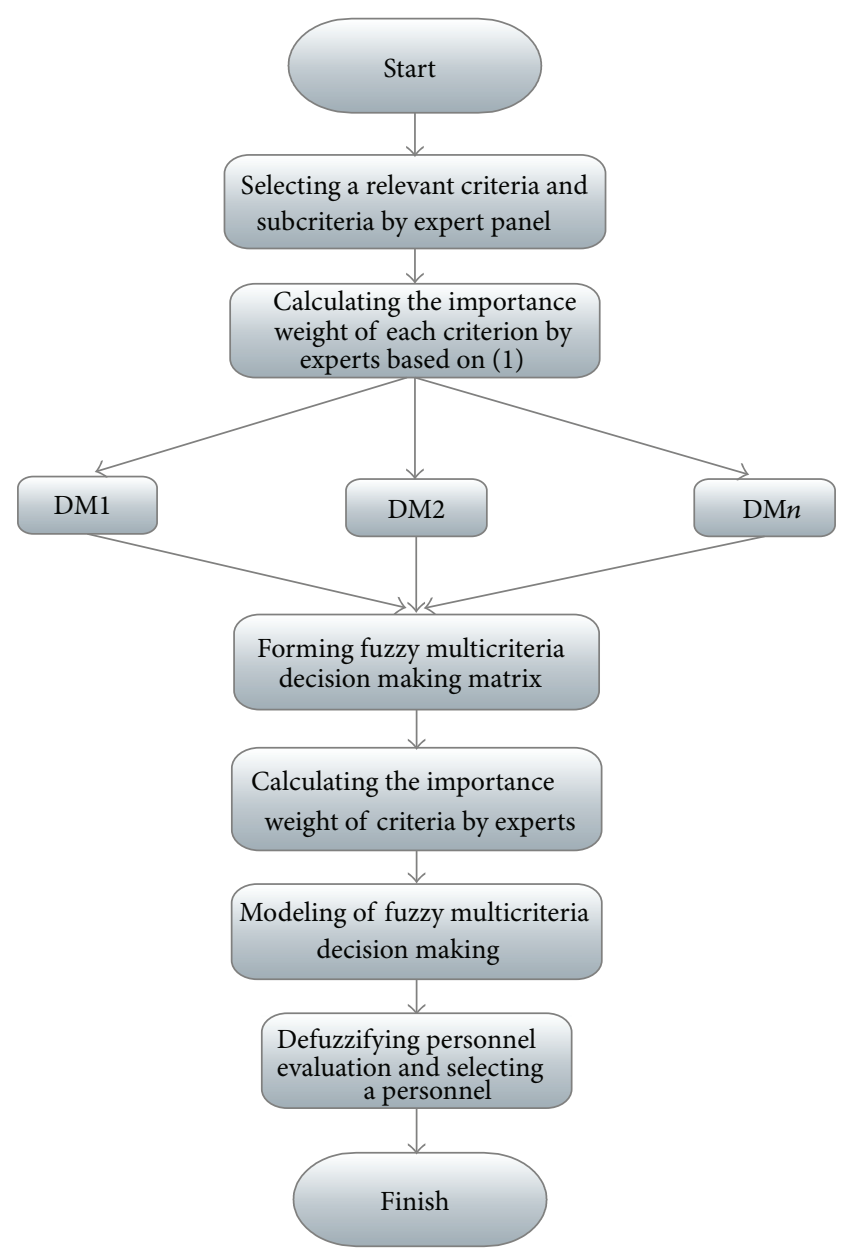

Figure 2: Modelling flowchart.

Phase 2 (calculating the importance weight of criteria). In terms of experts' opinions, the importance weights of subcriteria are calculated. Then, the importance weights of criteria are computed based on (1). 


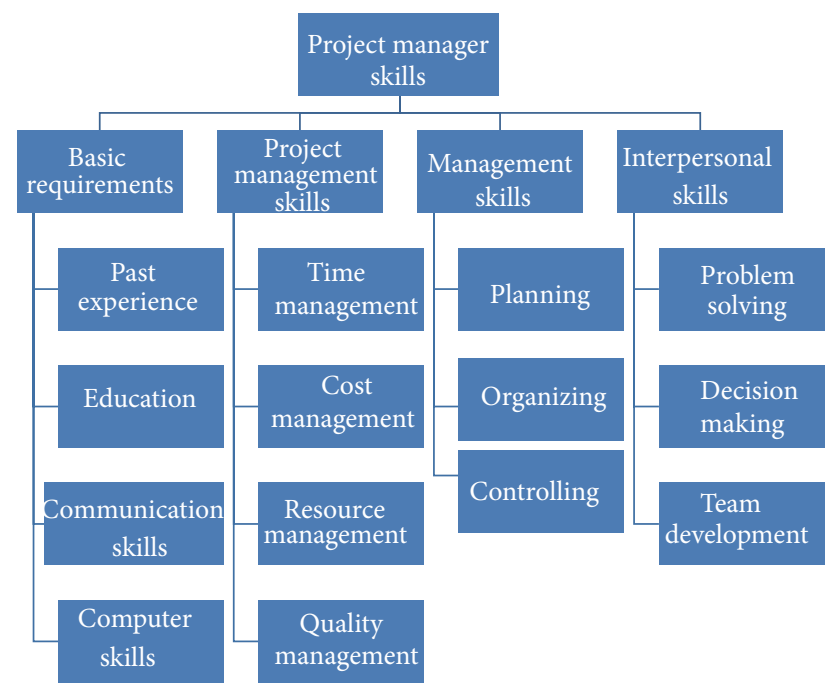

FIGURE 3: The hierarchical structure for project manager selection.

Phase 3 (establishing criteria and forming decision making matrix). Expert panel by NGT method determined the criteria and subcriteria for human resource selection. They had consensus over establishing criteria and forming the decision making matrix with regards to Table 1 . The four criteria were defined by the expert panel and also based on their knowledge and experiences. A group of experts was chosen to form an expert panel. Then, these experts were asked to specify the project manager selection criteria. The respondents were all among the company managers with relevant knowledge and more than five years of experience in project administration. Management had selected a panel consisting of procurement deputy, engineering deputy, executive deputy, administrative and financial deputy, planning deputy, quality and systems deputy, and inspection manager, safety manager, contracts manager, and the human resource department. A hierarchy is constructed in accordance with the criteria and factors as it is shown in Figure 3.

Phase 4 (modelling of FMCDM). Modelling procedures of FMCDM are described as follows.

(4.1) The first step to construct a FMCDM is to define universe set that is the element of universe = $\left\{\begin{array}{lllllll}1 & 2 & 3 & 4 & 5 & 6 & 7\end{array}\right\}$.

(4.2) Then a membership function for each criteria and alternatives is selected (Table 1). A "membership function" is a curve that defines how the value of fuzzy variable is mapped to a degree of membership between 0 and 1. Membership functions are used to calculate the degree of FMCDM in different values expressed by linguistic term. The verbal values are defined with regards to Table 2.

(4.3) Considering bell shape membership function, the decision matrix (fuzzy sets of criteria and alternatives)
TABLE 2: Linguistic definition of verbal values.

\begin{tabular}{lcc}
\hline Verbal values & Definition & Degree \\
\hline EL & Extremely low & 1 \\
VL & Very low & 2 \\
L & Low & 3 \\
M & Medium & 4 \\
H & High & 5 \\
VH & Very high & 6 \\
EH & Extremely high & 7 \\
\hline
\end{tabular}

is formed regarding Table 1 (fuzzy MCDM matrix) and (2). Consider

$$
\mu_{A}(x)=\frac{1}{1+d(x-c)^{2}},
$$

where $X \in[0,1]$ is the element of universe $U=\left\{\begin{array}{llll}1 & 2 & 3 & 4\end{array}\right.$ $\left.\begin{array}{lll}5 & 6 & 7\end{array}\right\}, c$ indicates the standard score for determining verbal (linguistic) value of the criteria and human resource, and $d$ determines the shape of the membership function (here $d=$ $0.2)$.

(4.4) Applying subsequent formula, the utility of decisions (human resource) is calculated using the following equation:

$$
\begin{gathered}
A_{i}=\left\{\left(\overline{C_{1}} \cup a_{i 1}\right) \bigcap\left(\overline{C_{2}} \cup a_{i 2}\right) \bigcap \cdots\left(\overline{C_{m}} \cup a_{i m}\right)\right\}, \\
A_{i}=\bigcap_{i=1}^{n}\left(\overline{C_{j}} \cup a_{i m}\right) .
\end{gathered}
$$

Phase 5 (selecting best human resource). By employing centre of gravity method, fuzzy outputs of human resource transform to crisp utility with regards to the following equation [54-57]:

$$
Z^{*}=\frac{\sum_{j=1}^{n} \mu_{A}\left(x_{j}\right) \cdot x_{j}}{\sum_{j=1}^{n} \mu_{A}\left(x_{j}\right)} .
$$

Ultimately, with regards to last step which determined crisp utility of human resource subsequently, the human resources are ranked.

\section{Numerical Example}

To validate the proposed model, a case study was conducted in a company. MAPNA is a project based organization that is engaged in development and implementation of power, oil and gas, railway transportation, and some other industrial projects. It has 371 employees and is located in Tehran. Fourteen individuals in this company have been able to obtain international certificate in professional project management (PMP). Since 1992, MAPNA has been involved in more than 85 projects valuing over 17 billion euro. Selecting project manager is a critical task for this company. Usually, 

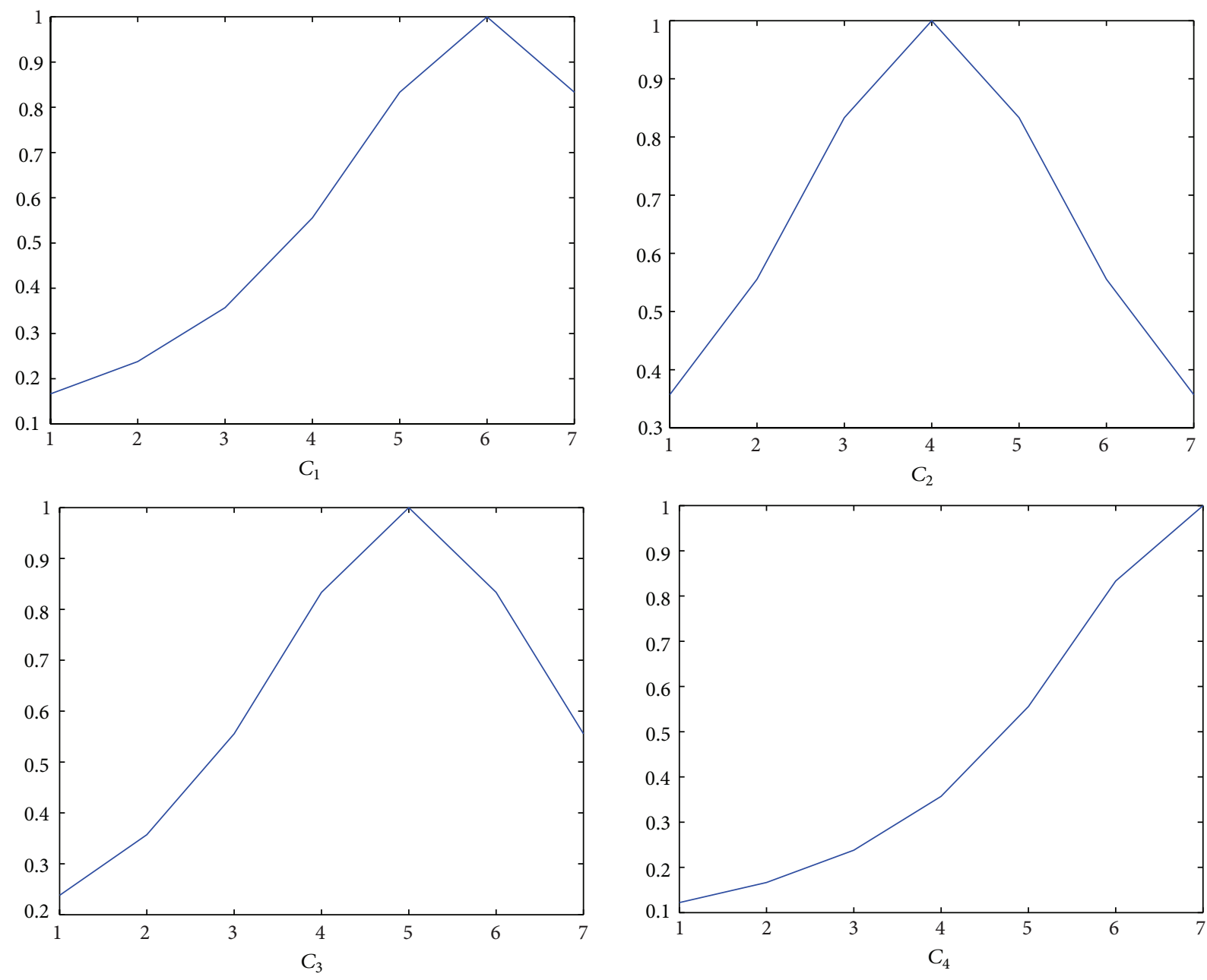

FIgURE 4: Membership function for the weighting of criteria $C_{1}-C_{4}$.

this selection is not done by a single person; however, a group of persons participate in the process. Also, the group of decision makers (expert panel) consists of decision makers from different organizational departments and high level managers. In order to determine which applicant is best for the job position from candidates, decision makers were invited. The committee was formed for evaluation of candidates and consists of procurement deputy, engineering deputy, executive deputy, administrative and financial deputy, planning deputy, quality and systems deputy, inspection manager, HSE manager, contracts manager, and the HR department.

Based on Phase 3, experts have consensus over establishing criteria and forming decision making matrix with regards to Table 1 through (1) and NGT method. The FMCDM is illustrated in Table 3.

Considering consensus of expert panels and taking Figure 3 into consideration, Phase 3 fuzzy weighting of criteria has been illustrated in Table 4 .

The membership function of criteria weighting under fuzzy space is depicted in Figure 4.
The fuzzy utility of each human resource is calculated by steps (4.3) and (4.4) and (2), (3), and (4) Then, by employing center of gravity method, fuzzy outputs of human resource are converted to crisp utility with regards to (4) as it is exhibited in Table 5.

Ultimately, with regards to the previous step that determined crisp utility of human resource subsequently, the human resources are ranked as illustrated in Table 6.

\section{Concluding Remarks}

The focus of this research was to contribute the concept of human resource selection by developing a decision making methodology that integrates group decision making and fuzzy linguistic evaluation. This study has clearly demonstrated that human resource selection can be improved in several ways by implementinga newfuzzy MCDM model. Firstly, decision makers can evaluate candidates based on their own verbal terms. Using linguistic variables in fuzzy environment is often comfortable for decision makers during 
TABLE 3: Fuzzy multicriteria decision matrix.

\begin{tabular}{lcccc}
\hline \multirow{2}{*}{ Human resource } & \multicolumn{4}{c}{ Criteria } \\
& $C_{1}$ & $C_{2}$ & $C_{3}$ & $C_{4}$ \\
\hline$P_{1}$ & $\mathrm{VH}$ & $\mathrm{H}$ & $\mathrm{L}$ & $\mathrm{EL}$ \\
$P_{2}$ & $\mathrm{EH}$ & $\mathrm{M}$ & $\mathrm{VH}$ & $\mathrm{H}$ \\
$P_{3}$ & $\mathrm{EL}$ & $\mathrm{L}$ & $\mathrm{H}$ & $\mathrm{M}$ \\
$P_{4}$ & $\mathrm{H}$ & $\mathrm{M}$ & $\mathrm{L}$ & $\mathrm{EL}$ \\
$P_{5}$ & $\mathrm{M}$ & $\mathrm{EH}$ & $\mathrm{EL}$ & $\mathrm{L}$ \\
$P_{6}$ & $\mathrm{M}$ & $\mathrm{M}$ & $\mathrm{H}$ & $\mathrm{EH}$ \\
$P_{7}$ & $\mathrm{~L}$ & $\mathrm{EL}$ & $\mathrm{H}$ & $\mathrm{L}$ \\
$P_{8}$ & $\mathrm{VL}$ & $\mathrm{M}$ & $\mathrm{L}$ & $\mathrm{H}$ \\
\hline
\end{tabular}

TABle 4: Fuzzy weighting of criteria $C_{1}-C_{4}$.

\begin{tabular}{lcccc}
\hline Criteria & $C_{1}$ & $C_{2}$ & $C_{3}$ & $C_{4}$ \\
\hline Fuzzy weighting & Very high & Medium & Extremely high & High \\
\hline
\end{tabular}

TABLE 5: Utility of strategic plans.

\begin{tabular}{lccccccc}
\hline$P_{1}$ & $P_{2}$ & $P_{3}$ & $P_{4}$ & $P_{5}$ & $P_{6}$ & $P_{7}$ & $P_{8}$ \\
\hline 0.4005 & 0.4607 & 0.3910 & 0.4563 & 0.3868 & 0.4567 & 0.3880 & 0.4562 \\
\hline
\end{tabular}

TABLE 6: Human resource ranking result.

\begin{tabular}{lcc}
\hline Number of human resources & Utility & Rank \\
\hline$P_{1}$ & 0.4005 & 5 \\
$P_{2}$ & 0.4607 & 1 \\
$P_{3}$ & 0.3910 & 6 \\
$P_{4}$ & 0.4563 & 3 \\
$P_{5}$ & 0.3868 & 8 \\
$P_{6}$ & 0.4567 & 2 \\
$P_{7}$ & 0.3880 & 7 \\
$P_{8}$ & 0.4562 & 4 \\
\hline
\end{tabular}

the evaluation stage. Secondly, by applying linguistic variables, less emphasis is placed on detailed data collection. In this methodology, the new linguistic reasoning for group decision making under uncertainty has been employed for evaluating human resource. The proposed model is able to aggregate subjective evaluation of the decision makers and offer an opportunity to perform more robust human resource selection procedures. For future research, it would be suggested to provide another effective mechanism in modeling the decision makers' preferences and to handle the imprecision of the human decision making process effectively in human resource selection problem.

\section{Conflict of Interests}

There is no conflict of interests for this research.

\section{Acknowledgment}

This study is supported by University Malaysia Pahang (UMP) Research Grant (RUD130375). The authors wish to thank UMP.

\section{References}

[1] I. T. Robertson and M. Smith, "Personnel selection," Journal of Occupational and Organizational Psychology, vol. 74, no. 4, pp. 441-472, 2001.

[2] C.-F. Chien and L.-F. Chen, "Data mining to improve personnel selection and enhance human capital: a case study in hightechnology industry," Expert Systems with Applications, vol. 34, no. 1, pp. 280-290, 2008.

[3] M. Dursun and E. E. Karsak, "A fuzzy MCDM approach for personnel selection," Expert Systems with Applications, vol. 37, no. 6, pp. 4324-4330, 2010.

[4] S. D. Pohekar and M. Ramachandran, "Application of multicriteria decision making to sustainable energy planning-a review," Renewable and Sustainable Energy Reviews, vol. 8, no. 4, pp. 365-381, 2004.

[5] H.-S. Shih, L.-C. Huang, and H.-J. Shyur, "Recruitment and selection processes through an effective GDSS," Computers and Mathematics with Applications, vol. 50, no. 10-12, pp. 1543-1558, 2005.

[6] M. Tavana, D. T. Kennedy, and P. Joglekar, "A group decision support framework for consensus ranking of technical manager candidates," Omega, vol. 24, no. 5, pp. 523-538, 1996.

[7] F. A. Taylor, A. F. Ketcham, and D. Hoffman, "Personnel evaluation with AHP," Management Decision, vol. 36, no. 10, pp. 679-685, 1998.

[8] R. Gibney and J. Shang, "Decision making in academia: a case of the dean selection process," Mathematical and Computer Modelling, vol. 46, no. 7-8, pp. 1030-1040, 2007.

[9] S.-K. Liao and K.-L. Chang, "Selecting public relations personnel of hospitals by analytic network process," Journal of Hospital Marketing and Public Relations, vol. 19, no. 1, pp. 52-63, 2009.

[10] S.-K. Liao and K.-L. Chang, "Select televised sportscasters for Olympic games by analytic network process," Management Decision, vol. 47, no. 1, pp. 14-23, 2009.

[11] S. Sorooshian and J. Dodangeh, "Modeling on performance drivers of project management," Advances in Environmental Biology, vol. 7, no. 13, pp. 3890-3894, 2013.

[12] H.-S. Shih, H.-J. Shyur, and E. S. Lee, "An extension of TOPSIS for group decision making," Mathematical and Computer Modelling, vol. 45, no. 7-8, pp. 801-813, 2007.

[13] E. H. Suh, D. H. Byun, and Y. S. An, "An approach to effective job placement in an organization: a case study," Human Systems Management, vol. 12, no. 2, pp. 129-143, 1993.

[14] R. S. Hooper, T. P. Galvin, R. A. Kilmer, and J. Liebowitz, "Use of an expert system in a personnel selection process," Expert Systems with Applications, vol. 14, no. 4, pp. 425-432, 1998.

[15] V. Cho and E. W. T. Ngai, "Data mining for selection of insurance sales agents," Expert Systems, vol. 20, no. 3, pp. 123132, 2003.

[16] A. Jessop, "Minimally biased weight determination in personnel selection," European Journal of Operational Research, vol. 153, no. 2, pp. 433-444, 2004.

[17] E. Jereb, U. Rajkovic, and V. Rajkovic, "A hierarchical multiattribute system approach to personnel selection," International Journal of Selection and Assessment, vol. 13, no. 3, pp. 198-205, 2005.

[18] M. Saidi Mehrabad and M. Fathian Brojeny, “The development of an expert system for effective selection and appointment of the jobs applicants in human resource management," Computers and Industrial Engineering, vol. 53, no. 2, pp. 306-312, 2007. 
[19] E. Herrera-Viedma and E. Peis, "Evaluating the informative quality of documents in SGML format from judgements by means of fuzzy linguistic techniques based on computing with words," Information Processing and Management, vol. 39, no. 2, pp. 233-249, 2003.

[20] L. A. Zadeh, "The concept of a linguistic variable and its application to approximate reasoning. I," vol. 8, pp. 199-249, 1975.

[21] P. P. Wang, Computing with Words, Wiley, New York, NY, USA, 2001.

[22] P. C. Chen, "A fuzzy multiple criteria decision making model in employee recruitment," International Journal of Computer Science and Network Security, vol. 9, no. 7, pp. 113-117, 2009.

[23] Z. Güngör, G. Serhadlioǧlu, and S. E. Kesen, "A fuzzy AHP approach to personnel selection problem," Applied Soft Computing Journal, vol. 9, no. 2, pp. 641-646, 2009.

[24] H.-T. Lin, "Personnel selection using analytic network process and fuzzy data envelopment analysis approaches," Computers and Industrial Engineering, vol. 59, no. 4, pp. 937-944, 2010.

[25] C.-T. Chen, "Extensions of the TOPSIS for group decisionmaking under fuzzy environment," Fuzzy Sets and Systems, vol. 114, no. 1, pp. 1-9, 2000.

[26] Y.-M. Wang and T. M. S. Elhag, "Fuzzy TOPSIS method based on alpha level sets with an application to bridge risk assessment," Expert Systems with Applications, vol. 31, no. 2, pp. 309-319, 2006.

[27] I. Mahdavi, N. Mahdavi-Amiri, A. Heidarzade, and R. Nourifar, "Designing a model of fuzzy TOPSIS in multiple criteria decision making," Applied Mathematics and Computation, vol. 206, no. 2, pp. 607-617, 2008.

[28] P. V. Polychroniou and I. Giannikos, "A fuzzy multicriteria decision-making methodology for selection of human resources in a Greek private bank," Career Development International, vol. 14, no. 4, pp. 372-387, 2009.

[29] A. Kelemenis and D. Askounis, "A new TOPSIS-based multicriteria approach to personnel selection," Expert Systems with Applications, vol. 37, no. 7, pp. 4999-5008, 2010.

[30] A. Kelemenis, K. Ergazakis, and D. Askounis, "Support managers' selection using an extension of fuzzy TOPSIS," Expert Systems with Applications, vol. 38, no. 3, pp. 2774-2782, 2011.

[31] W. Siler and J. J. Buckley, Fuzzy Expert Systems and Fuzzy Reasoning, John Wiley \& Sons, Hoboken, NJ, USA, 2005.

[32] G.-S. Liang and M.-J. J. Wang, "Personnel placement in a fuzzy environment," Computers and Operations Research, vol. 19, no. 2, pp. 107-121, 1992.

[33] G.-S. Liang and M.-J. J. Wang, "Personnel selection using fuzzy MCDM algorithm," European Journal of Operational Research, vol. 78, no. 1, pp. 22-33, 1994.

[34] S. B. Yaakob and S. Kawata, "Workers' placement in an industrial environment," Fuzzy Sets and Systems, vol. 106, no. 3, pp. 289-297, 1999.

[35] G. Capaldo and G. Zollo, "Applying fuzzy logic to personnel assessment: a case study," Omega, vol. 29, no. 6, pp. 585-597, 2001.

[36] A. Golec and E. Kahya, "A fuzzy model for competency-based employee evaluation and selection," Computers and Industrial Engineering, vol. 52, no. 1, pp. 143-161, 2007.

[37] L.-S. Chen and C.-H. Cheng, "Selecting IS personnel use fuzzy GDSS based on metric distance method," European Journal of Operational Research, vol. 160, no. 3, pp. 803-820, 2005.
[38] X. Bi and A.-D. Zhang, "Application of fuzzy analytical hierarchy process in selecting a project manager," in Proceedings of the 13th International Conference on Management Science and Engineering (ICMSE '06), pp. 1417-1421, October 2006.

[39] Z. Hui, W. Xue-qing, Y. Gang, and Z. Li-fu, "Study on engineering project manager selection," in Proceedings of the 4th International Conference on Wireless Communications, Networking and Mobile Computing (WiCOM '08), IEEE, 2008.

[40] L. Zhao, Y. Guo, and W. Cui, "The application of fuzzy comprehensive evaluation methods in the selection of a project manager," in Proceedings of the 4th International Conference on Computer Sciences and Convergence Information Technology (ICCIT '09), pp. 1387-1391, IEEE, November 2009.

[41] E. K. Zavadskas, Z. Turskis, J. Tamošaitiene, and V. Marina, "Multicriteria selection of project managers by applying grey criteria," Technological and Economic Development of Economy, vol. 14, no. 4, pp. 462-477, 2008.

[42] L. Zhao, Y. Guo, and W. Cui, "The application of fuzzy comprehensive evaluation methods in the selection of a project manager," in Proceedings of the 4th International Conference on Computer Sciences and Convergence Information Technology (ICCIT '09), pp. 1387-1391, November 2009.

[43] A. Rashidi, F. Jazebi, and I. Brilakis, "Neurofuzzy genetic system for selection of construction project managers," Journal of Construction Engineering and Management, vol. 137, no. 1, pp. 17-29, 2011.

[44] J. T. Ross, Fuzzy Logic with Engineering Applications, John Wiley \& Sons, Albuquerque, NM, USA, 2nd edition, 2004.

[45] C. Kahraman, Fuzzy Multi-Criteria Decision Making: Theory and Applications with Recent Developments, Springer, New York, NY, USA, 2008.

[46] M. Grabisch, "The application of fuzzy integrals in multicriteria decision making," European Journal of Operational Research, vol. 89, no. 3, pp. 445-456, 1996.

[47] J. J. Jassbi, R. Radfar, and R. Babaali, "Modeling based on multi objective decision making for determining of goals' appropriate selection," in Proceedings of the IEEE International Conference on Fuzzy Systems, pp. 1891-1896, IEEE, August 2009.

[48] H. J. Zimmermann, Fuzzy Set Theory and Its Applications, Kluwer, Boston, Mass, USA, 1996.

[49] M. Sugeno, Industrial Applications of Fuzzy Control, Elsevier Science, Amsterdam, The Netherlands, 1985.

[50] D. Liginlal and T. T. Ow, "Modeling attitude to risk in human decision processes: an application of fuzzy measures," Fuzzy Sets and Systems, vol. 157, no. 23, pp. 3040-3054, 2006.

[51] J.-H. Cheng, C.-M. Lee, and C.-H. Tang, "An application of fuzzy delphi and fuzzy AHP on evaluating wafer supplier in semiconductor industry," WSEAS Transactions on Information Science and Applications, vol. 6, no. 5, pp. 756-767, 2009.

[52] R. Bi and J.-Y. Wei, "Application of fuzzy ANP in production line selection evaluation indices system in ERP," in Proceedings of the IEEE International Conference on Automation and Logistics (ICAL '08), pp. 1604-1608, IEEE, September 2008.

[53] S. Sorooshian and A. Azizi, "Fuzzy bases," World Applies Sciences Journal, vol. 26, no. 10, pp. 1335-1339, 2013.

[54] J. Dodangeh, Modeling of Fuzzy Balanced Scorecard, in Department of Industrial Management [M.S. thesis], I.A.U, Science \& Research Branch, Tehran, Iran, 2006.

[55] J. Dodangeh, R. B. M. yusuff, and J. Jassbi, "Using topsis method with goal programming for best selection of strategic plans in BSC model," Journal of American Science, vol. 6, no. 3, pp. 136$142,2010$. 
[56] J. Dodangeh, M. Mojahed, and V. Nasehifar, "Ranking of strategic plans in balanced scorecard by using electre method," International Journal of Innovation, Management and Technology, vol. 1, no. 3, pp. 269-274, 2010.

[57] J. Dodangeh, J. Jassbi, M. Mousakhani, M. Anisseh, and R. Yusuff, "Priority of strategic plans in BSC model by using of Group Decision Making Model," in Proceedings of the IEEE International Conference on Industrial Engineering and Engineering Management (IEEM '08), pp. 471-475, December 2008. 


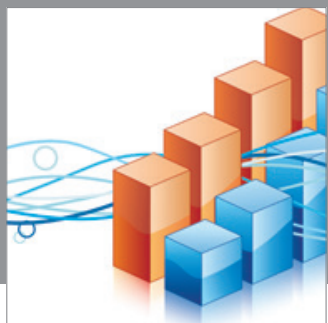

Advances in

Operations Research

mansans

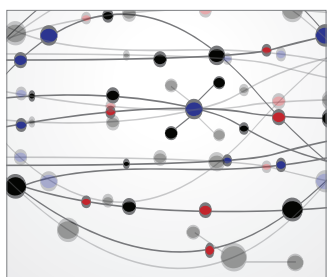

The Scientific World Journal
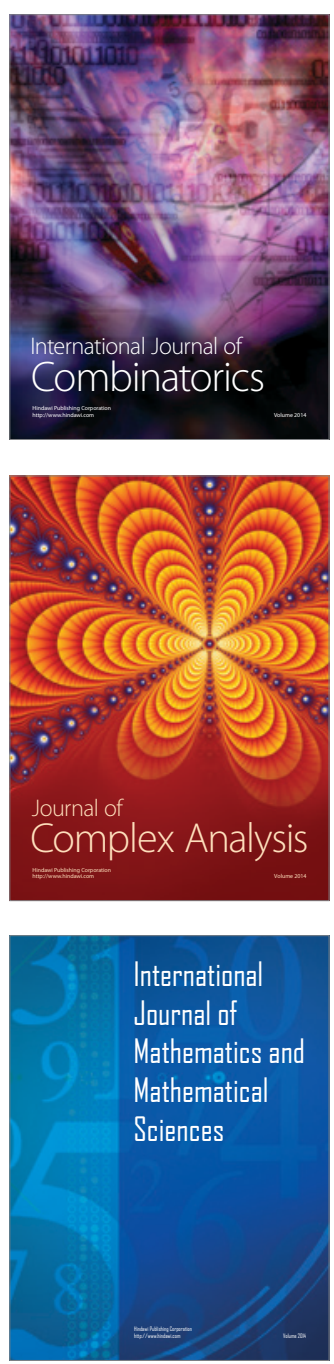
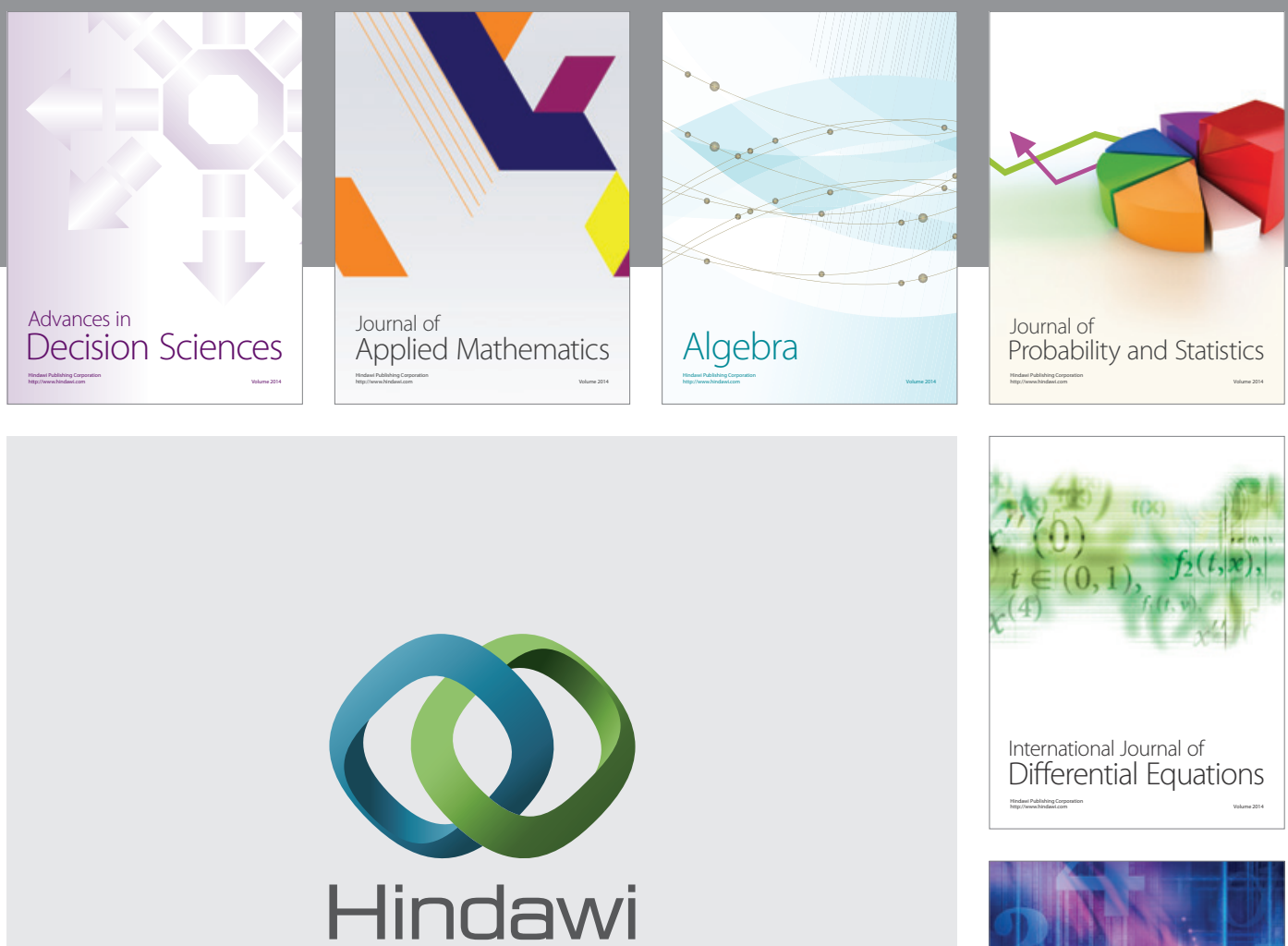

Submit your manuscripts at http://www.hindawi.com
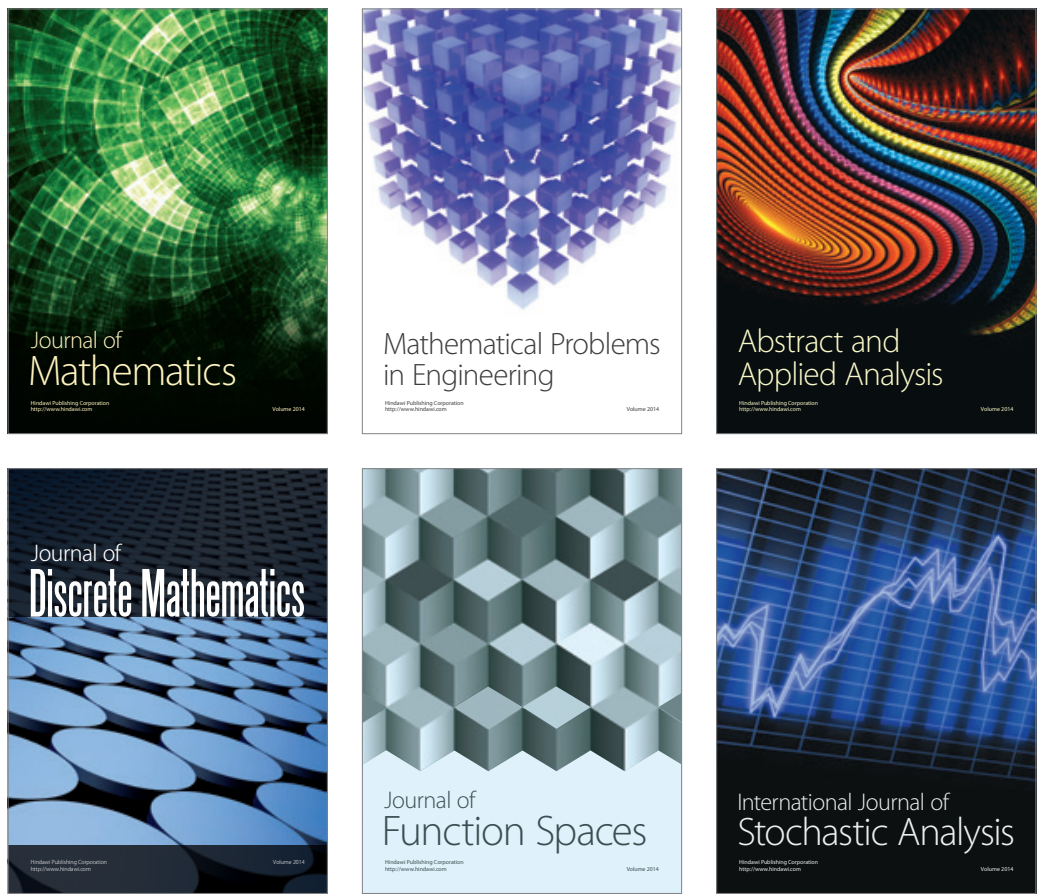

Journal of

Function Spaces

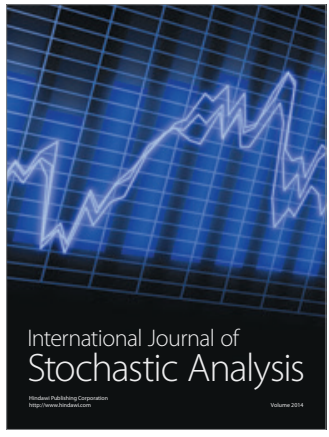

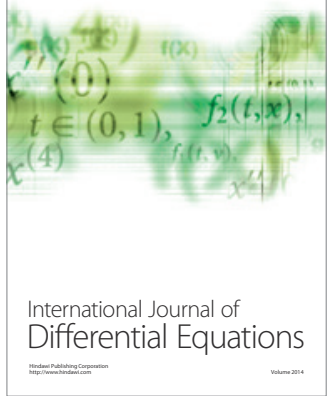
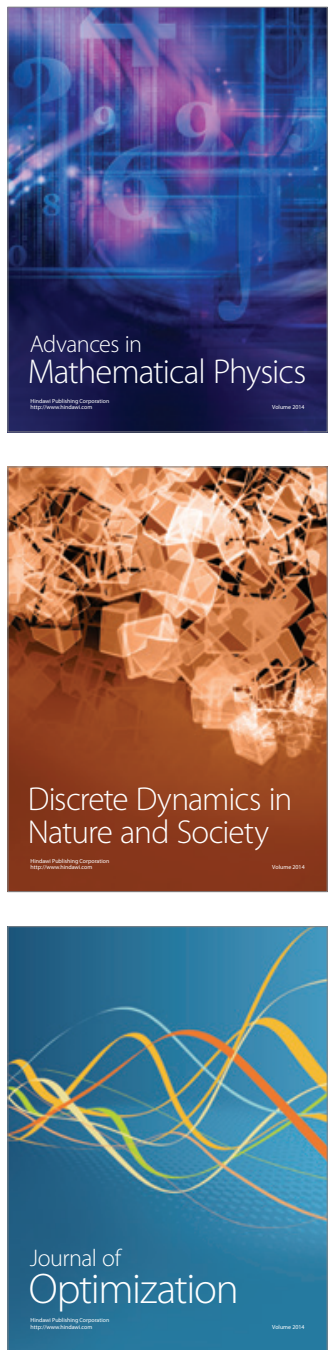